\title{
Photoperiodic control of meiosis in the male Syrian hamster (Mesocricetus auratus)
}

\author{
G. Breckon and A. H. Cawood* \\ M.R.C. Radiobiology Unit, Harwell, Didcot, Oxon OX11 ORD, U.K.
}

\begin{abstract}
Summary. Male Syrian hamsters exposed to short photoperiods of $6 \mathrm{~h} \mathrm{light/day}$ (6L:18D) show regression of the testes within 12 weeks. Chromosome preparations of the meiotic stages (pachytene, metaphase I (MI) and metaphase II (MII)), testicular weights relative to body weights, sperm counts, seminiferous tubule diameter and histological appearance were examined at intervals during regression and subsequent recovery in a long photoperiod (14L:10D). The fall of testicular weight was associated with the decrease in tubule diameter. Spermatogenesis and sperm count were reduced rapidly and finally ceased after 10 weeks in short days. The numbers of MI and MII cells relative to 100 pachytene cells progressively decreased during the short-day treatment, although the ratio of MI:MII stayed constant whenever there was meiotic activity (except in the first week of the recovery phase). This suggests that an increasing proportion of pachytene cells did not progress to MI with increased time in short days, but cells which did reach MI progressed to MII in the same proportions as in the control testes. Meiosis ceased after 10 weeks in short days. Recovery in the long days was marked by a peak in the number of MI and MII cells/100 pachytene cells soon after the return to long days. This preceded the return (to control values) of the sperm count by 10 weeks. Initial recovery in the first 3 weeks was very rapid in all the determined values.
\end{abstract}

\section{Introduction}

The Syrian hamster breeds in the spring and reproductive competence of the males is affected by change in the photoperiod (Elliot, 1981). Natural changes in testicular weight related to the autumnal equinox have been examined by Vendrely, Guerillot, Basserville \& De Lange (1971). The testes of adult hamsters require at least $12.5 \mathrm{~h}$ of light per day to maintain spermatogenesis and prevent degeneration (Gaston \& Menaber, 1967). Adult Syrian hamsters kept in a light period exceeding this have a relative testicular weight to body weight of about $3 \cdot 2 \%$. With a light period of $<12.5 \mathrm{~h}$ per day the relative testicular weight regressed to $0.39 \%$ in $10-12$ weeks (Elliot, 1981). Hormonal studies by Hoffman (1981) indicate that melatonin secretion from the pineal gland is essential for the photoperiodic control of reproduction in the hamster.

The studies outlined above have shown how photoperiod affects sperm production, testicular mass, and hormone concentrations. However, sperm production depends, ultimately, upon the successful completion of meiosis in spermatocytes derived from successive mitotic divisions of spermatogonia. Therefore, we have studied meiosis in the hamster to determine in what way the changes in reproductive competence and testicular morphology brought about by photoperiod are associated with changes in the activity of the germ cells.

* Present address: Department of Physiology and Biochemistry, Whiteknights, Reading, Berks RG6 2AJ, U.K. 


\section{Materials and Methods}

Animals and husbandry. We used 20 karyotypically normal (Breckon \& Goy, 1979) and four translocation ISH (ISH, $2 \mathrm{n}=43$, lacks one derivative chromosome (der 11) of a reciprocal translocation T (11:20)) (Breckon \& Savage, 1982) male hamsters, raised in our colony and maintained from birth in conditions of $14 \mathrm{~h}$ light (07:00-21:00 h GMT)/ $24 \mathrm{~h}$ at a temperature of $22 \pm 2^{\circ} \mathrm{C}$. All animals were adults aged 3 months at the start of the experiment. They were kept in groups of 2-4 in plastic rat cages, with bar tops and translucent white polypropylene bases. The animals were fed a pelleted diet (FFG(M): Dixon's, Ware, Herts, U.K.) and a weekly supplement of sunflower seeds and cabbage. The drinking water was chlorinated ( $15 \pm 4$ p.p.m. chlorine as sodium hypochlorite). The main animal room and the experimental chamber were illuminated with daylight-type fluorescent tubes at a light intensity of $360 \pm 25 \mathrm{~lx}$ within the cages. The productivity of the main colony, breeding performance, litter numbers and testis sizes were within the normal range throughout the period of this study.

Daylength treatment. Animals were transferred to an aluminium-alloy, ventilated light-proof box (kept in the same animal room) which was fitted with a time-switched fluorescent light of similar wavelength and intensity to that of the main colony. A light period of $6 \mathrm{~h}$ was followed by $18 \mathrm{~h}$ of darkness. A thermograph indicated a rise in temperature of $1-1.5^{\circ} \mathrm{C}$ during this light period. Animals remained in short-day conditions for 12 weeks, and were then returned to $14 \mathrm{~h}$ light/24 h for up to 15 weeks. Animals in Groups 10 and 11 were maintained in 6L:18D, for 14 and 16 weeks respectively, to check the rate of spontaneous recovery in continuous short days.

Testicular sampling. At times indicated in Text-fig. 1 two animals from each group were killed. Animals in Groups 1, 2 and 3 were killed during regression (short days), and those in Groups 4-11 during the recovery period (long days). Two animals were killed as controls. The 4 translocation animals were included as one of the 2 animals in Groups C, 5, 7 and 9. At $2 \mathrm{~h}$ before killing, an injection of $0.05 \mathrm{ml}$ colchicine (at $8 \mathrm{mg} / 10 \mathrm{ml} 0.154 \mathrm{M}-\mathrm{NaCl}$ ) was given into the right testis. The colchicine has the property of condensing and separating chromosomes at the metaphase stages, improving the ability to analyse metaphase II chromosomes and those of mitotic metaphase. In extensive meiotic studies performed in this laboratory no systematic differences have been found between the two testes. A sperm count was always performed with samples taken from both left and right epididymis. The sperm samples were diluted with $1 \cdot 15 \%(\mathrm{w} / \mathrm{v})$ sodium chloride (saline isotonic for hamsters; mean osmotic pressure $349 \mathrm{mosmol}$ ) and counted in an improved Neubauer haemocytometer using phase-contrast optics. No differences in the sperm quality, i.e. motility and

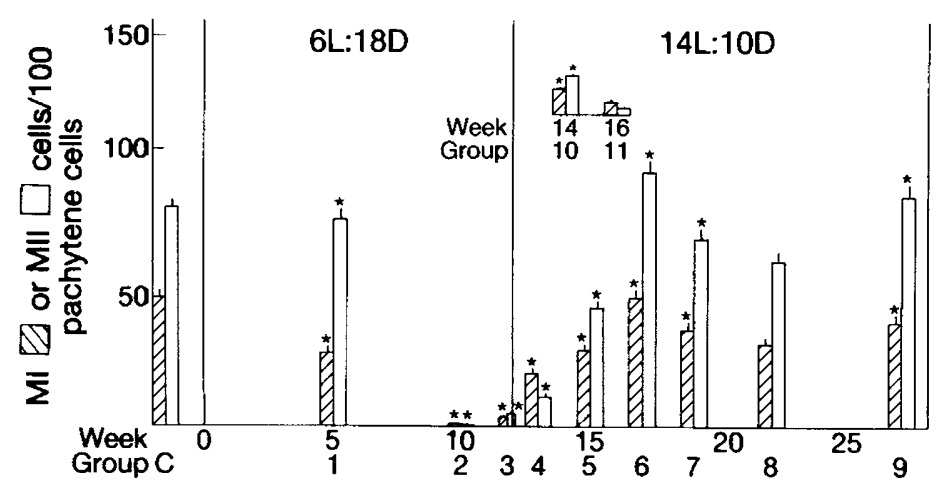

Text-fig. 1. Ratios of metaphase I and metaphase II cells/100 pachytene cells in hamster testes sampled during photoregression (6L:18D) and recovery (14L:10D). Values are mean \pm s.e.m. for MI and MII counts, per 100 late pachytene cells for 2 testes and 2 animals per column. ${ }^{*} P<0.05$ or less compared with equivalent value for preceding group (Student's $t$ test). 
morphology, were found between the controls and animals kept in different photoperiods. The animals were weighed after death, and both testes were removed and weighed. Seminiferous tubule samples were taken for the air-dried preparations of pachytene and metaphase I and II cells (Breckon, 1982) and histological examination. To show the effect of photoperiod on the size of the testes, the combined testicular weights are expressed as a percentage of body weight, since it has been shown that body weight and testicular weight are linearly related in hamsters (Thomas et al., 1979). The testicular material was fixed in Bouin's fluid, sectioned at $5 \mu \mathrm{m}$ and stained with Ehrlich's haematoxylin and eosin. Tubule diameter was measured using an eyepiece micrometer. The tubules selected for measurement were those that were circular and 30 such measurements were taken from each testis. The control material was from karyotypically normal animals of equivalent age from the main colony.

Chromosome preparations. The seminiferous tubules were removed from the tunica, and were mechanically macerated in a $2.35 \%(\mathrm{w} / \mathrm{v})$ trisodium citrate solution to give a cell suspension. An aliquant equivalent to half the testis was taken and given a 15 -min hypotonic treatment with a $1.8 \%(\mathrm{w} / \mathrm{v})$ solution of trisodium citrate, by adding water to the cells in the $2.35 \%$ sodium citrate solution. The cells were fixed in methanol/acetic acid $(3: 1, \mathrm{v} / \mathrm{v})$ and the preparations were air dried.

\section{Cellular analysis}

\section{Results}

From the air-dried preparations of the right testis 100 metaphase I cells (when present) were scored for abnormalities such as aneuploidy, separated XY chromosomes and multivalents, and metaphase II cells for $\mathrm{X}$ chromosome segregation anomalies. No abnormalities of these kinds were found in any of the 1050 metaphase I cells, 980 metaphase II cells or 1300 pachytene cells (as synaptonemal complexes) scored. Pachytene stages persisted in reasonable numbers in all hamsters except those with fully regressed testes (Groups 2 and 3).

To give some measure of the progress of cells through meiosis, the number of cells at metaphase I (MI) and at metaphase II (MII) are expressed relative to 100 pachytene cells (Text-fig. 1).

\section{Histology of the tubules (Table 1)}

After 10 weeks in short days there was almost a complete arrest of meiosis and mean tubule diameter fell from 360 to $130 \mu \mathrm{m}$. In control tubules, the lumen diameter was $0.66-0.75 \%$ of the total tubule diameter, with a ring of spermatogonial cells, Sertoli cells and a lumen filled with spermatozoa. In Group 1 hamsters there was some decrease in tubule diameters and the lumen ceased to have the regular radial pattern of spermatozoa. A decrease in the number and continuity of the ring of spermatogonia was also observed. Group 2 hamsters showed a marked decrease in tubule diameter, a virtual absence of a lumen and spermatozoa, and an almost complete arrest of meiosis. A reduction in the number of spermatogonia, and irregularity of their distribution were also observed. In Group 3 animals, at the end point of regression in this study, there was no observable meiotic activity, no spermatozoa, and a thickening of the lamina propria.

Relative testicular weight fell during the short-day treatment. The variation in the size of the interstitial cell patches that was observed in voles during the regression cycle (Grocock \& Clarke, 1974) did not occur in the hamster. The sperm count fell dramatically by $49 \%$ after 5 weeks in short days. However, this fall in sperm count was not matched by an equivalent reduction in the numbers of MI and MII cells $/ 100$ pachytene cells, indicating that the reduction in the sperm count at this time is essentially a post-meiotic phenomenon. During the 5-10-week period of short days the sperm count fell again ( 51 to $2.5 \%$ ) and, as indicated in Text-fig. 1, meiotic activity had almost ceased. After 12 weeks in short days, there was an indication of a recovery of the tubule diameter and resumed meiotic activity.

In the recovery phase, after return to $14 \mathrm{~L}: 10 \mathrm{D}$, the reverse pattern was found, with a rapid return of tubule and meiotic activity within 7 days after the daylength change. By the 5th week of 
Table 1. Effect of photoperiod treatments on relative testicular weight, sperm count and tubule diameter in hamsters

\begin{tabular}{|c|c|c|c|c|c|c|}
\hline \multirow[b]{2}{*}{ Group } & \multirow{2}{*}{$\begin{array}{l}\text { No. of } \\
\text { animals }\end{array}$} & \multicolumn{2}{|c|}{$\begin{array}{l}\text { Photoperiod treatment } \\
\text { (weeks) }\end{array}$} & \multirow{2}{*}{$\begin{array}{c}\text { Relative } \\
\text { testicular wt } \\
(\%) \dagger\end{array}$} & \multirow{2}{*}{$\begin{array}{l}\text { Sperm count } \\
\left(\times 10^{-3} / \mathrm{ml}\right) \ddagger\end{array}$} & \multirow{2}{*}{$\begin{array}{l}\text { Mean tubule } \\
\text { diam. } \S \\
(\mu \mathrm{m})\end{array}$} \\
\hline & & 6L:18D & 14L:10D & & & \\
\hline Control & $2(1 \mathrm{~T})^{*}$ & - & From birth & $3 \cdot 10 \pm 0.08$ & $179 \cdot 2 \pm 2 \cdot 71$ & $364 \pm 22$ \\
\hline 1 & 2 & 5 & - & $2 \cdot 73 \pm 0 \cdot 15$ & $92.0 \pm 0.45$ & $332 \pm 20$ \\
\hline 2 & 2 & 10 & - & $1.21 \pm 0.12$ & $0.60 \pm 0.32$ & $131 \pm 9$ \\
\hline 3 & 2 & 12 & - & $0.34 \pm 0.04$ & zero & $112 \pm 13$ \\
\hline 4 & 2 & 12 & 1 & $0.45 \pm 0.02$ & $15 \cdot 10 \pm 0 \cdot 45$ & $186 \pm 17$ \\
\hline 5 & $2(1 T)^{*}$ & 12 & 3 & $1.85 \pm 0.03$ & $22.7 \pm 0.21$ & $238 \pm 15$ \\
\hline 6 & 2 & 12 & 5 & $2.03 \pm 0.07$ & $25.6 \pm 0.63$ & $334 \pm 20$ \\
\hline 7 & $2(1 \mathrm{~T})^{*}$ & 12 & 7 & $2.44 \pm 0.13$ & $39.8 \pm 0.97$ & $347 \pm 15$ \\
\hline 8 & 2 & 12 & 10 & $2.48 \pm 0.17$ & $44.6 \pm 0.79$ & $341 \pm 14$ \\
\hline 9 & $2(1 T)^{*}$ & 12 & 15 & $3.01 \pm 0.14$ & $221 \cdot 5 \pm 0 \cdot 77$ & $372 \pm 24$ \\
\hline 10 & 2 & 14 & - & $0.40 \pm 0.03$ & $10 \cdot 6 \pm 0.33$ & $207 \pm 19$ \\
\hline 11 & 2 & 16 & - & $0.61 \pm 0.07$ & $20.8 \pm 0.44$ & $236 \pm 13$ \\
\hline
\end{tabular}

*Including one $1 \mathrm{SH}$ translocation animal.

$\dagger$ (Weight of testes/weight of body) $\times 100 \%$ ( 4 testes/ 2 animals per point, each point represents the mean \pm s.e.m. of 2 observations).

$\ddagger$ Mean \pm s.e.m. for epididymides ( 2 animals).

$\S$ Each point represents the mean \pm s.e.m. per 30 tubule diameters per testis, 4 testes per point.

the recovery phase (Group 6) there were high numbers of metaphase I and metaphase II cells, indicating a pronounced surge of meiotic activity that preceded sperm production (Text-fig. 1). The sperm count did not return to control values until the 15 th week of long days (Group 9).

In animals of Groups 10 and 11 the sperm counts and tubule diameters had recovered values equivalent to those found in animals returned to long days for 1 week (Group 4), but meiotic activity was delayed. Values for the $1 \mathrm{SH}$ translocation animals did not appear to be different from those of the normal animal of the pair.

\section{Discussion}

The study reported here shows that the loss in short days and gain in long days of weight by the testes of the Syrian hamster are related to tubule diameter. The fall and rise in relative testicular weight is almost parallel to the fall and rise in mean tubule diameter. This is in contrast to the situation during senescence in this species in which tubule diameter does not change significantly (Soderwall, Van Brocklin \& Ramey, 1950; G. Breckon, unpublished). The meiotic data, especially the cessation of metaphase I, metaphase II and the low level of pachytene activity, together with the histological appearance of the tubules in hamsters with fully regressed testes in short photoperiods, have a similarity to some of the examples of infertile human males (Chaganti \& German, 1979; Johannisson et al., 1983) and mice (Searle, Beechey, Evans \& Kirk, 1983). Schürmeyer, Knuth, Belkein \& Nieschlag (1984) reported a reversible azospermia and a decrease in testicular volume by $50 \%$ in $10-12$ weeks in a man using an anabolic steroid: meiosis was not studied. In the hamster the sperm count falls dramatically in the initial 3 weeks of the short-day treatment, and the sensitivity of the sperm count to daylength indicates the importance of exercising control of daylength in breeding colonies of Syrian hamsters. Near zero values of metaphase I and II cells and of sperm numbers and a very low level of pachytene stage cells were observed at 10 weeks in a short photoperiod.

After return to long days, recovery is rapid. Plısma FSH concentrations are significantly 
elevated within 24 h of transfer of hamsters from short to long days (Steger, Bartke, Matt, Soares \& Talamantes, 1981) and are part of the stimulatory trigger of the early recovery of regressed testis in long days.

By 5 weeks after the change to long days an increase in the numbers of metaphase I and metaphase II cells is seen in hamsters, similar to that observed at puberty in the mouse (Goetz, Chandley \& Speed, 1984). This wave of meiotic activity coincides in the recovery period with the high elevation of serum FSH concentrations (Stetson, Watson-Whitmyre \& Matt, 1977) and precedes the rise to normal control values of the numbers of metaphase I and metaphase II cells, and of sperm counts by about 10 weeks. By the use of a 'natural' system, i.e. photoperiod control of testicular regression and recovery, spermatogenesis, and in particular the meiotic stages of metaphase I and metaphase II, can be synchronized in any number of adult male Syrian hamsters. This may enable additional studies of the effects of environmental agents on spermatogonial stem cells to be undertaken. Radiation studies on photocontrolled testes are in progress.

We thank Dr J. R. K. Savage for helpful discussion, Mr D. G. Papworth for performing the statistical analyses, Denise Malowany for technical assistance, John Bowler for animal husbandry, and Caroline Barker and David Beaney for histology.

\section{References}

Breckon, G. (1982) A modified hypotonic treatment for increasing the frequency and quality of meiotic metaphases from spermatocytes of the Syrian hamster. Stain Technol. 57, 349-354.

Breckon, G. \& Goy, P. (1979) Routine chromosome screening in Syrian hamsters (Mesocricetus auratus) using orbital sinus blood. Lab. Anim. 13, 301-304.

Breckon, G. \& Savage, J.R.K. (1982) Homozygous deficiency: Syrian hamsters with only 42 chromosomes. Cytogenet. Cell Genet. 33, 85-294.

Chaganti, R.S.K. \& German, J. (1979) Human male infertility, probably genetically determined, due to defective meiosis and spermatogenic arrest. Am. J. hum. Genet. 31, 634-641.

Elliot, J.A. (1981) Circadian rhythms, entrainment and photoperiodism in the Syrian hamster. In Biological Clocks in Seasonal Reproductive Cycles, pp. 203-217. Eds B. K. Follett \& D. E. Follett. Wrights, Bristol.

Gaston, S. \& Menaber, M. (1967) Photoperiodic control of hamster testis. Science, N.Y. 158, 925-928.

Goetz, P., Chandley, A.C. \& Speed, R.M. (1984) Morphological and temporal sequence of meiotic prophase development at puberty in the male mouse. J. Cell Sci. 65, $249-263$.

Grocock, C.A. \& Clarke, J.R. (1974) Photoperiodic control of testis activity in the vole (Microtus agrestis). J. Reprod. Fert. 39, 337-347.

Hoffman, K. (1981) The role of the pineal gland in the photoperiodic control of seasonal cycles in hamsters. In Biological Clocks in Seasonal Reproductive Cycles, pp. 237-250. Eds B. K. Follett \& D. E. Follett. Wrights, Bristol.
Johannisson, R., Gropp, A., Winkling, H., Coerdt, W., Rehder, H. \& Schwinger, E. (1983) Down's Syndrome in the male: reproductive pathology and meiotic studies. Hum. Genet. 63, 132-138.

Schürmeyer, T., Knuth, U.A., Belkein, L. \& Nieschlag, E. (1984) Reversible azospermia induced by the anabolic steroid 19-nortestosterone. Lancet ii, $417-420$.

Searle, A.G., Beechey, C.V., Evans, E.P. \& Kirk, M. (1983) Two new X-autosome translocations in the mouse. Cytogenet. Cell Genet. 3, 279-292.

Soderwall, A.L., Van Brocklin, G. \& Ramey, R. (1950) Senescent histological appearances in reproductive systems of aged male and female hamsters. Anat. Rec. 188, 603-604.

Steger, R.W., Bartke, A.S., Matt, K.S., Soares, M.J. \& Talamantes, F. (1981) Neuroendocrine changes in male hamsters following photostimulation. J. exp. Zool: 229, 467-474.

Stetson, M., Watson-Whitmyre, N. \& Matt, S.K. (1977) Termination of photorefractoriness in Golden hamsters-photoperiod requirements. J. exp. Zool. 202, 81-88.

Thomas, R.G., London, J.E., Drake, G.A., Jackson, D.E., Wilson, J.S. \& Smith, D.M. (1979) The Golden Hamster Quantitative Anatomy with Age. Los Alamos Scientific Laboratory LASL-79-58.

Vendrely, E.C., Guerillot, C., Basserville, C. \& De Lange, C. (1971) Poids testiculaires et spermatogenese du hamster d'or au cours du cycle saisonnier. $C$. $r$. Séanc. Soc. Biol. 165, 1562-1565.

Received 24 December 1984 